\title{
$O$ ato de amamentar: um estudo qualitativo
}

| 1 Najara Barbosa Rocha, ${ }^{2}$ Artênio José Isper Garbin,

${ }^{3}$ Cléa Adas Saliba Garbin, ${ }^{4}$ Suzely Adas Saliba Moimaz I

Resumo: O objetivo do estudo foi analisar, de forma qualitativa, o conhecimento e percepção de um grupo de mulheres, bem como analisar os determinantes que influenciam a prática do aleitamento materno. Foi adotada a metodologia da pesquisa qualitativa, utilizando como referencial a teoria de representações sociais. Foram entrevistadas 27 gestantes, por um único entrevistador, durante o pré-natal e acompanhadas até o sexto mês do bebê, quando já estavam completamente desmamados. A análise compreensiva das falas permitiu verificar os fatores que levam a mãe a amamentar seus filhos, como "proteção do bebê" e "amor materno". Também foram verificados os motivos que levaram as mães a desmamarem seus filhos, sendo citados "a falta de leite"/"leite secou" e o "trabalho". Verificou-se, a partir das representaçóes das mães, que mesmo que elas demonstrassem conhecimento sobre as propriedades do leite, não foi garantido o sucesso da prática de amamentação natural.

> Palavras-chave: aleitamento materno; desmame; pesquisa qualitativa.

\author{
1 Mestre e Doutoranda em \\ Odontologia Preventiva \\ e Social da Faculdade de \\ Odontologia de Araçatuba-SPI \\ UNESP. Endereço eletrônico: \\ najaraunesp@hotmail.com \\ ${ }^{2}$ Coordenador do Curso de \\ Pós-graduação em Odontologia \\ Preventiva e Social; Professor \\ Adjunto da Faculdade de \\ Odontologia de Araçatuba-SP/ \\ UNESP. \\ ${ }^{3}$ Professora Adjunta da \\ Faculdade de Odontologia de \\ Araçatuba-SP/UNESP. \\ ${ }^{4}$ Vice-coordenadora do \\ Curso de Pós-graduação em \\ Odontologia Preventiva e \\ Social; Professora Adjunta da \\ Faculdade de Odontologia de \\ Araçatuba-SP/UNESP.
}

Recebido em: 24/11/2009. Aprovado em: 03/05/2010. 
$\mathrm{O}$ ato de amamentar aparenta ser simples e um instinto nato, mas para seu sucesso, requer ensinamentos e um complexo conjunto de condições interacionais no contexto social da mulher e do filho (BASTOS et al., 2004). A amamentação é comportamento social, mutável conforme épocas e sofreu transformações durante a história (ALMEIDA; NOVAK, 2004). Este ato é influenciado pela família e pelo meio social em que a mulher vive (JAVORSKI et al., 2004).

$\mathrm{O}$ aleitamento materno traz benefícios tanto para o bebê, quanto para nutriz, mas mesmo assim sua prática está muito aquém do que se é esperado e recomendado pelas organizaçôes internacionais e nacionais, ou seja, de forma exclusiva até os seis meses e complementar a outros alimentos até os dois anos de idade ou mais (WHO, 2007; BRASIL, 2008). Deste modo, é de fundamental importância definir os motivos que levam ao desmame precoce, com o intuito de proporcionar o maior tempo possível de aleitamento às crianças.

São vários os fatores que estão interligados com o abandono desta prática alimentar, agindo de forma negativa ou positiva, sendo os principais: nível socioeconômico, grau de escolaridade da mãe, idade da mãe, trabalho materno, urbanização, condições do parto, incentivo do cônjuge e parentes, bem como a intenção da mãe de amamentar e experiência anterior a esta (ESCOBAR et al., 2002; ARAÚJO et al., 2008).

Outro aspecto que merece atenção especial é a importância do profissional de saúde no incentivo ao aleitamento materno, promovendo, apoiando e instruindo a nutriz, através do acompanhamento pré-natal e após nascimento, alojamento conjunto durante a puericultura, entre outros. Quando definimos os motivos que podem contribuir com o desmame precoce, é possível agir melhor na prevenção desses fatores e de forma mais eficaz (ESCOBAR et al., 2002).

Assim, este estudo ${ }^{1}$ se propõe a analisar quais os conhecimentos e percepções das mulheres nutrizes sobre o aleitamento materno influenciam na continuidade da prática da amamentação.

\section{Metodologia}

A investigação foi realizada no município de Araçatuba, Estado de São Paulo, Brasil, utilizando-se a abordagem qualitativa de investigação social, por sua adequação ao estudo de significados e atitudes dos personagens de estudo. 
Buscou-se obter informações suficientes permitir uma análise aprofundada das falas, envolvendo a questão central do tema pesquisado, o aleitamento materno. O foco do estudo voltou-se para a qualidade atribuída pelas informantes ao fenômeno investigado.

A população de estudo constituiu-se de 27 mulheres matriculadas no programa pré-natal do serviço público de cidades do Noroeste do Estado de São Paulo, as quais haviam desmamado seus filhos, considerando desmame precoce a cessão da prática de aleitamento materno antes dos seis meses de idade.

Em relação à amostragem, devido à natureza qualitativa do estudo, foi considerado como maior importância o aprofundamento e a compreensão do discurso destas mães, objetivando assim, o esgotamento das categorias e saturação das falas dos sujeitos de pesquisa (BARDIN, 2004).

Esta pesquisa faz parte de um estudo de coorte, prospectivo com gestantes acompanhadas desde o pré-natal até os seus filhos completarem 36 meses de idade, para a análise dos aspectos relacionados com a saúde do binômio mãe-filho. Foram selecionadas as gestantes que frequentaram pelo menos seis consultas durante o acompanhamento pré-natal, tiveram gestação a termo (mais de 37 semanas de gestação) e iniciaram o processo de desmame antes do sexto de mês de vida do bebê.

Foi realizado um estudo piloto, para validação e adequação do instrumento de coleta de dados, aferição das dificuldades encontradas, capacitação e calibração dos pesquisadores. A pesquisa foi realizada em duas etapas. No primeiro momento, foram realizadas entrevistas domiciliares e na própria Unidade Básica de Saúde, com gestantes para a verificação do conhecimento e percepção sobre o aleitamento materno e condições socioeconômicas da população de estudo. Todos os dados coletados foram registrados em fichas clínicas específicas e obtido o termo de consentimento livre esclarecido das participantes da pesquisa.

Numa segunda etapa, foram feitas visitas domiciliares após o nascimento dos bebês até o desmame destes, para verificar os motivos de desmame precoce e os fatores determinantes, que influenciam para este desfecho. A partir dessa fundamentação, são explicitados os passos e os procedimentos adotados, uma vez que tal detalhamento se revela como requisito de rigor na epistemologia qualitativa.

Para cumprir com os objetivos e realizar uma análise sobre os fenômenos estudados, foram adotados os conceitos de pesquisa qualitativa. Como princípio 
teórico e metodológico, foi escolhida a técnica das representações sociais, a qual analisa a forma como os indivíduos de uma determinada sociedade, pertencentes a um determinado grupo social, expressam sua realidade e a interpretam, dependendo do seu nível de conhecimento pautado na sua experiência do cotidiano. Sob esse foco é que se pretendeu entender as representações de amamentação das mães (MOREIRA; OLIVEIRA, 2000).

Para a coleta de dados, foram realizadas entrevistas semiestruturadas, orientadas por um questionário previamente elaborado com questôes sobre: conhecimentos e percepção das mães sobre aleitamento materno; experiência prévia sobre amamentação; vantagens do leite materno para mãe e filho e pretensão de amamentar durante a gestação. As respostas foram transcritas na íntegra como foram respondidas, analisadas pela técnica qualitativa de Análise de Conteúdo, preconizada por Bardin (2004). Houve a categorização das respostas e análise em profundidade dos conteúdos manifestos pelos atores sociais envolvidos (BARDIN, 2004). Esta análise indicou uma convergência das categorias empíricas em subtemas: experiência anterior sobre amamentação; desejo de amamentar; conhecimento e percepção da mãe sobre amamentação; dificuldades vivenciadas; motivos de desmame; apoio familiar; orientação sobre a amamentação durante pré-natal e lactação.

Este estudo foi aprovado pelo Comitê de Ética e Pesquisa em Seres Humanos da Faculdade de Odontologia de Araçatuba (FOA/UNESP), processo no 200601471, e se enquadra na modalidade de pesquisa de risco mínimo, bem como foi respeitada a Resolução no 196/96 do Conselho Nacional de Saúde, e suas resoluções complementares relativas à pesquisa em seres humanos. Todas as mães entrevistadas receberam informações sobre os objetivos do estudo e tomaram ciência de que a não-participação não lhe acarretaria prejuízo algum e que os dados coletados não seriam utilizados de forma individual.

\section{Resultados}

As características pessoais das mães e os aspectos relacionados aos filhos estão descritos na tabela 1 . As mulheres caracterizam-se por serem jovens (idade média 23,4 anos), brancas (59,3\%), com nível escolaridade médio (55,5\% com o ensino médio completo), renda familiar baixa (55,5\% recebiam menos que dois salários mínimos) e a maioria vivia com seus parceiros (70,3\%). 
Tabela 1 - Características pessoais das mães e os aspectos relacionados aos fillhos ( $\mathrm{n}=27$ ), Araçatulba, 2009

\begin{tabular}{|c|c|c|c|c|c|c|c|c|}
\hline \multicolumn{6}{|c|}{ Mãe } & \multicolumn{3}{|c|}{ Bebê } \\
\hline $\mathrm{N}^{\circ}$ & $\begin{array}{l}\text { Idade } \\
\text { (anos) }\end{array}$ & Escolaridade & Estado civil & Profissão & Cor & Sexo & $\begin{array}{c}\mathrm{AE} \\
(\text { meses) }\end{array}$ & $\begin{array}{c}\text { Duração } \\
\text { Amamentação }\end{array}$ \\
\hline 1 & 22 & $\mathrm{MC}$ & Amasiada & Do lar & Branca & F & 0 & 1 \\
\hline 2 & 37 & $\mathrm{FC}$ & Viúva & Estudante & Negra & $M$ & 1 & 5 \\
\hline 3 & 27 & SI & Casada & Autônoma & Branca & $M$ & 2 & 5 \\
\hline 4 & 18 & $\mathrm{MC}$ & Amasiada & Autônoma & Branca & $\mathrm{F}$ & 0 & 4 \\
\hline 5 & 20 & MI & Amasiada & $\begin{array}{c}\text { Funcionária } \\
\text { Privada }\end{array}$ & Branca & F & 0 & 5 \\
\hline 6 & 14 & MI & Amasiada & Do lar & Branca & $\mathrm{F}$ & 1 & 1 \\
\hline 7 & 34 & MC & Casada & $\begin{array}{c}\text { Funcionária } \\
\text { Privada }\end{array}$ & Parda & M & 0 & 5 \\
\hline 8 & 32 & $\mathrm{MC}$ & Amasiada & Autônoma & Branca & M & 0 & 2 \\
\hline 9 & 17 & $\mathrm{MC}$ & Amasiada & Autônoma & Branca & $\mathrm{F}$ & 1 & 3 \\
\hline 10 & 22 & $\mathrm{MC}$ & Casada & $\begin{array}{c}\text { Funcionária } \\
\text { Pública }\end{array}$ & Branca & M & 0 & 4 \\
\hline 11 & 29 & FI & Amasiada & Do lar & Parda & $M$ & 1 & 3 \\
\hline 12 & 18 & SI & Solteira & Estudante & Branca & $\mathrm{F}$ & 0 & 3 \\
\hline 13 & 27 & FI & Amasiada & Do lar & Parda & $\mathrm{F}$ & 0 & 0 \\
\hline 14 & 22 & $\mathrm{FC}$ & Divorciada & Do lar & Parda & M & 0 & 2 \\
\hline 15 & 32 & SI & Casada & $\begin{array}{c}\text { Funcionária } \\
\text { Privada }\end{array}$ & Parda & F & 0 & 5 \\
\hline 16 & 20 & $\mathrm{FC}$ & Amasiada & Do lar & Parda & $\mathrm{F}$ & 0 & 3 \\
\hline 17 & 22 & SC & Casada & $\begin{array}{c}\text { Funcionária } \\
\text { Pública }\end{array}$ & Branca & $\mathrm{F}$ & 0 & 0 \\
\hline 18 & 21 & $\mathrm{MC}$ & Casada & Do lar & Branca & $\mathrm{F}$ & 0 & 1 \\
\hline 19 & 31 & $\mathrm{MC}$ & Casada & Do lar & Branca & M & 0 & 0 \\
\hline 20 & 30 & MC & Casada & $\begin{array}{c}\text { Funcionária } \\
\text { Privada }\end{array}$ & Branca & F & 1 & 5 \\
\hline 21 & 31 & SC & Solteira & $\begin{array}{c}\text { Funcionária } \\
\text { Privada }\end{array}$ & Branca & F & 0 & 1 \\
\hline 22 & 16 & MI & Solteira & Estudante & Branca & M & 1 & 1 \\
\hline 23 & 21 & FI & Solteira & $\begin{array}{c}\text { Funcionária } \\
\text { Privada }\end{array}$ & Negra & $\mathrm{F}$ & 2 & 5 \\
\hline 24 & 30 & FI & Solteira & Do lar & Negra & $\mathrm{F}$ & 0 & 4 \\
\hline 25 & 22 & MI & Casada & Do lar & Parda & $\mathrm{F}$ & 2 & 5 \\
\hline 26 & 18 & $\mathrm{MC}$ & Amasiada & Autônoma & Branca & $\mathrm{F}$ & 0 & 4 \\
\hline 27 & 30 & FI & Solteira & Do lar & Negra & $\mathrm{F}$ & 0 & 4 \\
\hline
\end{tabular}

Abreviaturas: Escolaridade:FI-ensino fundamental incompleto; FC-ensino fundamental completo; MI-ensino médio incompleto; MC-ensino médio completo; SI-ensino superior incompleto e SCensino superior completo. Sexo: F-feminino e M-masculino. AE=aleitamento exclusivo. 
A análise das falas das mães permitiu agrupar os assuntos por significados comuns, dividindo em temas e subtemas, que estão expostos a seguir.

\section{Experiência anterior sobre amamentação}

A falta de experiência pode ser um fator de risco para o desmame (ARAÚJO et al., 2008). Neste estudo, $40,7 \%$ das mães estavam na primeira gestação, isto é, não têm experiência em amamentar. Para as mães de "primeira viagem", é importante orientar e motivar a prática de amamentar, sendo mais fácil assimilar o conhecimento e com maior disposição para aprender, pois não tiveram nenhuma experiência que influencia negativamente para este ato (ICHISATO; SHIMO, 2001; RAMOS; ALMEIDA, 2003). Por isso, o Ministério da Saúde, tendo em vista o risco de desmame entre as primíparas, enfatiza a atenção necessária para mulheres desta categoria (BRASIL, 2008).

Para o restante das mães que já estavam no segundo filho ou mais, é importante que a mulher coloque suas vivências e experiências anteriores em prática, pois a decisão de amamentar está diretamente relacionada ao que ela já viveu (RAMOS; ALMEIDA, 2003). Neste estudo, a maioria amamentou seus filhos anteriores $(76,5 \%)$, durante em média quase nove meses. Sobre o motivo de desmame, foram citados a escassez ou falta de leite e o fato de os filhos não quererem ou não aceitarem mais o peito. Estes aspectos foram evidenciados pelas falas: "um filho não quis mais [...] e o outro chorava de fome, tendo que dar leite pra ele mamá também [...] depois ele não quis mais", "o meu leite secou", "o meu leite vinha pouco e era fraquinho [...] o bebê chorava muito"). Quanto às que tiveram experiência negativa anterior, é importante trabalhar com seus medos e anseios, mostrando o correto manejo de amamentar e promovendo, assim, essa prática.

\section{Desejo de amamentar}

Todas as mulheres deste estudo mostraram interesse em amamentar seus filhos durante a gestação, por um período de dez meses em média. As representações desta vontade de amamentar ficaram evidenciadas nas seguintes falas: "claro que eu vou amamentar", "é super importante amamentar, por isso vou dar de mamar sim", "ah vou sim, se eu tenho é para isso neh".

Um dos fatores para o sucesso do aleitamento é o desejo da mãe, demonstrado durante a gestação, de amamentar seu filho no peito. 


\section{Conhecimento e percepção da mãe sobre amamentação}

Quanto ao conhecimento das gestantes sobre o tempo ideal de amamentação no peito e a amamentação exclusiva, houve muitas respostas diferentes das informações encontradas na literatura científica sobre este período, mostrando que o conhecimento das mulheres nutrizes sobre o tempo de amamentação é menor que o tempo preconizado na literatura científica ou pelas organizações de saúde, ou seja, de forma exclusiva durante os primeiros seis meses de vida e de complementar até dois anos de idade ou mais. A média de tempo respondida para aleitamento total foi de 11,2 meses (valores respondidos de 4 a 24 meses) e de amamentação exclusiva foi de 4,9 meses em média (valores respondidos de 0 a 8 meses).

A diferença entre o conhecimento científico sobre o tempo de amamentação e o verificado pelas falas das entrevistadas nos faz pensar que campanhas que tragam informações consideradas adequadas sobre o aleitamento possam incentivar a amamentação exclusiva no peito, o crescimento e desenvolvimento infantil (RAMOS; ALMEIDA, 2003).

No acompanhamento da prática de aleitamento materno destas mães, elas não a amamentaram nem 0,4 meses em média exclusivamente e três meses em média no aleitamento total, padrões bem aquém do que elas pretendiam e do recomendado pelas organizações de saúde, tais como, exclusivamente durante os primeiros seis meses de vida da criança e de forma complementar até a criança atingir dois anos de idade ou mais.

As representações das mães sobre o aleitamento materno se concentraram em três vertentes: amor materno; proteção do leite para o bebê e benefícios à mãe.

Amamentar qualifica a mulher como uma boa mãe. O amor materno está diretamente relacionado com a amamentação no peito (JAVORSKI et al., 2004). As representações das mães deste estudo sobre o amor materno se concentraram nas falas: "carinho que você sente ao amamentar"; "dá muito prazer"; "estou dando carinho"; "o contato com a criança, o calor humano".

$\mathrm{O}$ vínculo e o contato com a criança citado sobre o aleitamento materno não são representados pelo uso de mamadeira, que artificializa a relação afetiva e impede o contato direto (JAVORSKI et al. 2004). O significado de proteção do leite materno aos bebês está diretamente relacionado com as vantagens do aleitamento materno no crescimento e desenvolvimento normal infantil. Esta vertente foi verificada nas falas: "evita pegar muita doença”; “dá mais saúde”; “é 
igual a uma vacina para o bebê"; "evita resfriados"; "fica mais saudável”; "não tem risco de doenças, [...] tem muitos nutrientes"; "por que tem menos risco de pegar infecção"; "o leite do peito é mais saudável"; "é bom pra imunidade do bebê".

$\mathrm{O}$ discurso analisado denotou que as informaçōes difundidas pela mídia e pelas campanhas de políticas de saúde sobre aleitamento estão sendo incorporadas (JAVORSKI et al., 2004). Mesmo as mulheres não sabendo o tempo ideal para amamentar, elas sabem das propriedades do leite materno e a importância para o crescimento e desenvolvimento infantil.

Além do contato direto e o vínculo estabelecido com o filho com a amamentação no peito, encontramos na fala das mães estudadas outras vantagens pra elas desta prática alimentar, tais como: "evita o câncer de mama”; "evita o câncer de útero"; "é bom pra nossa saúde"; "volta o corpo ao natural [...] mais rapidamente"; "emagrece mais rápido". Além de citar também a praticidade e facilidade do leite e a questão da economia de dinheiro: "é mais fácil, tá pronto"; "sai quentinho e eu não tenho que preparar mamadeiras"; "economizo um dinheirão, sem comprar leite"; “já que tenho leite eu dou”.

As mulheres se preocupam muito com a vaidade, temem engordar, por isso o emagrecimento mais acelerado de mulheres nutrizes, favorecem a prática do aleitamento. Por outro lado, é citado na literatura que as mães têm medo de ficarem com as mamas caídas (ICHISATO; SHIMO, 2001) - esta representação não está presente nas falas das entrevistadas deste estudo.

A praticidade de amamentar no peito é um fator positivo para a mulher moderna, que necessita trabalhar e ainda cuidar da família e do lar, pois o aleitamento materno é a forma mais prática de se ter um leite pronto e em temperatura adequada, quando comparado ao preparo de uma mamadeira (ICHISATO; SHIMO, 2001).

\section{Dificuldades vivenciadas}

Nas falas de dez mães entrevistadas, foram evidenciadas dificuldades que tiveram com a amamentação no peito: "meu peito empedrou"; "começou a rachar e sangrou"; "doía demais quando eu amamentava"; "ele inchava sempre e doía".

As intercorrências mamárias são diretamente relacionadas como fator negativo à prática de aleitamento materno. Estas podem ser evitadas com a adoção de medidas preventivas ou curativas durante o pré-natal e no acompanhamento das 
mães durante a lactação (RAMOS; ALMEIDA, 2003). Daí a importância do acompanhamento longitudinal na prática do aleitamento materno dos serviços públicos de saúde, pelos agentes comunitários de saúde, durante o pré-natal e principalmente durante a lactação.

\section{Motivos de desmame}

Com ênfase nas falas das mães sobre os motivos que desmamaram seus filhos, foram encontrados quatro subtemas diferentes: o filho não aceitou mais o peito; a falta de leite ou que leite secou; doença da mãe e o trabalho materno. Como exemplo destes discursos, as mães responderam: "o leite não desceu"; "chorava de fome, [...] comecei a dar Nan, assim ele não quis mais"; "por que o leite secou"; "por que a criança não quis mais"; "por que ela não conseguia pegar o peito"; "por causa que eu não tinha bico"; "por causa do meu trabalho"; "por que eu tenho que trabalhar"; "voltei a trabalhar".

Quando a mãe diz que o filho não quer mais o peito, de certa maneira, este motivo está ligado com as representações nas falas de: "falta de leite" ou "leite insuficiente" Assim o filho permanece com fome e torna-se necessário que ela complemente a alimentação, causando posteriormente o desmame.

A "falta de leite", "leite insuficiente" ou "leite secou" são respostas que denotam a responsabilização da mulher para o desmame da criança (fracasso), visão criada no modelo higienista (ALMEIDA; NOVAK, 2004; ICHISATO; SHIMO, 2001). A literatura mostra que os índices de hipogaláctia (insuficiência de leite) são muito baixos $(1,5 \%)$ e que, do ponto de vista biológico, as mães têm capacidade de produzir quantidade de leite suficiente para atender ao crescimento adequado da criança (ALMEIDA; NOVAK, 2004; RAMOS; ALMEIDA, 2003; ICHISATO; SHIMO, 2001).

O trabalho materno só apareceu como motivo de desmame quando os bebês estavam no quarto e quinto meses de acompanhamento, período que geralmente termina a licença maternidade, e por isso a mãe desmama seu filho. Por esta razão, o retorno das mulheres ao trabalho, no quarto ou quinto mês do puerpério, é um fator prejudicial à continuidade da amamentação.

No Brasil, a licença-maternidade é de quatro meses, tempo insuficiente para a promoção da prática do aleitamento materno exclusivo (BRASIL, 1988). Em 2010, entrou em vigor uma lei aprovada em setembro do ano de 2008, pelo Governo 
1302 Federal, que cria o Programa Empresa Cidadã, destinado à prorrogação da licençamaternidade para seis meses mediante concessão de incentivo fiscal, incentivando, portanto, a prática de aleitamento materno exclusivo (BRASIL, 2008).

\section{Apoio familiar}

A maioria das mulheres estudadas $(74,1 \%)$ teve o apoio familiar para amamentar seus filhos, proveniente dos seus maridos.

A família exerce grande influência nas decisões da mulher pra amamentar seu filho no peito, mas provavelmente ela, família ou os familiares, não estão preparados para ajudar (MOREIRA; OLIVEIRA, 2000). No estudo de Ichisato e Shimo (2001), as mães recebem informações de pessoas que elas têm total confiança, principalmente das avós, e estas influenciam negativamente na prática do aleitamento materno, pois elas com frequência estimulam a inserção de chá na alimentação, para evitar as cólicas. Essa introdução diminui a proteção do leite materno contra processos infecciosos, assim como a duração do aleitamento materno (MASCARENHAS et al., 2006).

$\mathrm{O}$ marido exerce influência positiva na prática do aleitamento materno (PONTES et al., 2008), pois a mulher leva em consideração o que os maridos ou parceiros dizem, e assim motivam e encorajam-nas a amamentar.

\section{Orientação sobre a amamentação durante pré-natal e lactação}

A maioria das mães $(88,9 \%)$ teve orientações sobre amamentação e quase todas receberam estas informações de enfermeiras, no hospital, logo após o nascimento dos bebês, mostrando a importância deste profissional da saúde para o incentivo da prática de aleitamento materno.

Poucas mulheres foram orientadas antes do nascimento (55,6\%) e muito menos acompanhadas durante a lactação (18,5\%). Estes números são preocupantes, pois a mulher precisa ser assistida e acompanhada para que possa desempenhar bem o papel da mulher nutriz (ALMEIDA; NOVAK, 2004).

Só a informação ou orientação não basta para que as mulheres tenham sucesso em sua experiência de amamentar ou fiquem motivadas a fazê-lo. É preciso dar condições concretas para que mães e bebês vivenciem esse processo de forma prazerosa e com eficácia (BORGES; PHILIPPI, 2003) 


\section{Considerações finais}

A partir das representações das entrevistadas desta pesquisa, podemos concluir que embora as mulheres nutrizes tenham conhecimentos sobre as propriedades do leite materno e de algumas de suas vantagens, isto não foi suficiente para a manutenção da continuidade da amamentação.

Embora apareça nas falas das entrevistadas que a amamentação é considerada um ato natural e instintivo, fatores individuais, familiares e sociais aparecem como desafios a serem enfrentados para o sucesso desta prática.

\section{Referências}

ALMEIDA, J.A.G.; NOVAK, F.R. Amamentação: um híbrido natureza-cultura. $J$ Pediatr., v. 80, n. 5, 2004. Disponível em: http://www.scielo.br/scielo.php?script=sci_ arttext\&pid=S0021-75572004000700002\&lng=pt. Acesso em: 25 jan. 2009.

ARAÚJO, O.D. et al. Aleitamento materno: fatores que levam ao desmame precoce. Rev Bras enferm., v. 61, n. 4, p. 488-492, 2008. Disponível em: http://www.scielo.br/scielo. php?script=sci_arttext\&pid=S0034-71672008000400015\&lng=pt. Acesso em: 25 jan. 2009. BARDIN L. Análise de conteúdo. 3. ed. São Paulo: Ed. 70, 2004.

BASTOS, G.B.P.; MOTA, J.A.C.; NEHMY, R.M.Q. Nutrição infantil no final do séc XVIII. Rev Med Minas Gerais, v. 14, n. 1, Suppl 3, p. S73-S7, 2004.

BORGES, A.L.V.; PHILIPPI, S.T. Opinião de mulheres de uma unidade de saúde da família sobre a quantidade de leite materno produzido. Rev Latino-Am Enfermagem, v. 11, n. 3, p. 287-292, 2003. Disponível em: http://www.scielo.br/scielo.php?script=sci_ arttext\&pid=S0104-11692003000300004\&lng=. Acesso em: 25 jan. 2009.

BRASIL. Ministério da Saúde. Lei no 11.770, de 9 de setembro de 2008. Cria o Programa Empresa Cidadã, destinado à prorrogação da licença-maternidade mediante concessão de incentivo fiscal, e altera a Lei no 8.212, de 24 de julho de 1991. Pub. L. no 11.770 (Set. 9, 2008). BRASIL. Ministério da Saúde. Aleitamento materno. Disponível em: http://portal.saude. gov.br/portal/saude/area.cfm?id_area=1251. Acesso em 06 de ago. de 2008.

BRASIL. Senado Federal. Constituição da República Federativa do Brasil, de 5 de dezembro de 1988. Brasília, 1988. Disponível em: http://www.fazenda.sp.gov.br/legislacao/codec/docs/const_fed_art7.pdf. Acesso em: 25 jan. 2009.

ESCOBAR, A.M.U. et al. Aleitamento materno e condiçōes sócio-econômico-culturais: fatores que levam ao desmame precoce. Rev Bras Saúde Matern Infant., v. 2, n. 3, p. 253261, 2002. 
ICHISATO, S.M.T.; SHIMO, A.K.K. Aleitamento materno e as crenças alimentares. Rev Latino-Am Enfermagem, v. 9, n. 5, p. 70-76, 2001. Disponível em: http://www.scielo.br/scielo. php?script=sci_arttext\&pid=S0104-11692001000500011\&lng=pt. Acesso em: 25 jan. 2009. JAVORSKI, M. et al. As representações sociais do aleitamento materno para mães de prematuros em unidade de cuidado canguru. Rev Latino-Am Enfermagem, v. 12, n. 6, p. 890-898, 2004. Disponível em: http://www.scielo.br/scielo.php?script=sci_arttext\&pid=S0104$11692004000600007 \& \operatorname{lng}=$ pt. Acesso em: 25 jan. 2009.

MASCARENHAS, M.L.W. et al. Prevalência de aleitamento materno exclusivo nos três primeiros meses de vida e seus determinantes no Sul do Brasil. J Pediatr., v. 82, n. 4, p. 289-294, 2006.

MOREIRA, A.S.P.; OLIVEIRA, D.C. Estudos interdisciplinares de representação social. 2. ed. Goiânia: AB Editora, 2000.

PONTES, C.M.; ALEXANDRINO, A.C.; OSÓRIO, M.M. Participação do pai no processo da amamentação: vivências, conhecimentos, comportamentos e sentimentos. J. Pediatr., v. 84 , n. 4, p. 357-364, 2008. Disponível em: http://www.scielo.br/scielo.php?script=sci_ arttext\&pid=S0021-7557200800400012\&Ing=en. Acesso em: 15 jun. 2009.

RAMOS, C.V.; ALMEIDA, J.A.G. Alegaçóes maternas para o desmame: estudo qualitativo. J Pediatr., v. 79, n. 5, p. 385-390, 2003. Disponível em: http://www.scielo.br/scielo. php?script=sci_arttext\&pid=S0021-75572003000500004\&lng=pt. Acesso em: 25 jan. 2009. WORLD HEALTH ORGANIZATION. Indicators for assessing breastfeeding practices. Geneva: WHO; 2007. Disponível em: http://www.who.int/nutrition/publications/iycf_indicators_for_peer_review.pdf. Acesso em: 15 jun. 2008.

\section{Nota}

${ }^{1}$ Este estudo recebeu auxílio pesquisa Fapesp n. 06/61615-9 e fez parte de dissertação de mestrado, bolsista Capes. 


\section{Abstract}

The act of breastfeeding: a qualitative study This study aimed to perform a qualitative analysis of the knowledge and perception of a group of women, and to assess the determinants that influence breastfeeding. It adopted the qualitative research method, based on the theory of social representations. Twenty-seven pregnant women were interviewed by only one interviewer during prenatal period and the babies were accompanied until the sixth month after birth or until they were completely weaned. The comprehensive speech analysis allowed verifying factors that made mothers breastfeed their babies, like: "baby protection" and "mother's love". We also observed the reasons that made mothers wean their babies: "lack of milk" / "the milk dried" and "job". Through the mother's representations we could notice that even if they showed knowledge about properties and advantages of milk, it did not guarantee the successful natural breastfeeding practice.

Key words: breastfeeding; weaning; qualitative research. 